\title{
Happiness and Its Association with Mindfulness: A Non- systematic Review
}

\author{
Deepak Salvi ${ }^{1}$, Vikas Gaur ${ }^{2}$, Anil Tambi ${ }^{3}$, Tanushi Tambi ${ }^{4}$
}

\begin{abstract}
The concepts of happiness and related engagement practices have attracted common life since ancient times. Happiness is an emotional experience that has evolved over the millennia to accommodate the rapidly changing needs of the individual in particular and the environment at large. It mainly refers to people's subjective appraisals of their lives in terms of well-being and typically includes a global assessment of all aspects of a person's life. Mindfulness, on the other hand, refers to the self-regulation of attention to one's experiences in the present moment with curiosity, openness, and acceptance and thus promotes the adaptations of higher-order needs which in turn lead to positive emotions and ultimately happiness. Available literature points to a positive link between mindfulness and happiness, and this paper contributes to the existing body of knowledge by consolidating the findings. Widespread acceptance and dissemination of mindfulness practice represent the new emerging process of engagement with happiness that provides a beginning empirical foundation. Future research can attempt to throw some light on this relationship and to determine what facets may be correlating and mediating the mindfulness meditation-happiness relationship in terms of life satisfaction and well-being.

Keywords: Acceptance, Adaptation, Engagement, Happiness, Mindfulness.

Journal of Mahatma Gandhi University of Medical Sciences \& Technology (2021): 10.5005/jp-journals-10057-0144
\end{abstract}

\section{INTRODUCTION}

Emotions are fundamental to human life and are considered as the critical component of the survival mechanism. ${ }^{1,2}$ In addition to several other emotional experiences, happiness was also selected through evolution to promote adaptation. ${ }^{2-4}$ From an evolutionary perspective, human emotions and needs evolved to help motivate adaptive behaviors and ultimately happiness. ${ }^{5,6}$ With the evolution of humans, the quest for happiness started and later it became the most pervasive attribute of humans. Happiness as an evolutionarily powerful antidote to our survival concerns has evolved overtime to accommodate the rapidly changing needs of the individual in particular and the environment at large. ${ }^{6,7}$ Moreover, with the rapid growth in human needs and expectations, the perception regarding happiness has also evolved and transformed accordingly.

Overtime, it is witnessed that life satisfaction has gradually transformed from biological or basic needs to social and other higher needs. However, with the increasing awareness of higherorder needs, i.e., self-actualization needs and authentic happiness as described by Seligman ${ }^{8}$ have now become a new evolutionary force. Recently, Geher and Wedberg ${ }^{9}$ to understand the link between the concept of survival adaptation and happiness fully stated that psychologists should include both positive psychology and the use of evolutionary psychology principles to help people and communities experience more positive and fulfilling lives. They also described the happiness facet of the human experience in terms of its evolutionary origins and proposed how psychologists can guide people to optimally experience such positive phenomena in their everyday lives. Moreover, through this integration of knowledge, the lives of people can also be advanced by studying the factors that increase positive outcomes such as life satisfaction and happiness.

Mindfulness refers to the awareness that arises through paying attention to purpose ${ }^{10}$ and is believed to cultivate the non-judgmental attention or self-regulation of attention to one's
${ }^{1}$ Department of Clinical Psychology, Mahatma Gandhi Medical College and Hospital, Mahatma Gandhi University of Medical Sciences, Jaipur, Rajasthan, India

2,4 Department of Psychiatry, Mahatma Gandhi Medical College and Hospital, Mahatma Gandhi University of Medical Sciences, Jaipur, Rajasthan, India

${ }^{3}$ Department of Psychiatry, Sawai Maan Singh Medical College and Hospital, Jaipur, Rajasthan, India

Corresponding Author: Vikas Gaur, Department of Psychiatry, Mahatma Gandhi Medical College and Hospital, Mahatma Gandhi University of Medical Sciences, Jaipur, Rajasthan, India, Phone: +91 9829158478, e-mail:drvikasgaur@gmail.com

How to cite this article: Salvi D, Gaur V, Tambi A, et al. Happiness and Its Association with Mindfulness: A Nonsystematic Review. J Mahatma Gandhi Univ Med Sci Tech 2021;6(1):25-28.

Source of support: Nil

Conflict of interest: None

experiences in the present moment with curiosity, intention, attitude, openness, and acceptance. ${ }^{11,12}$ Several studies point to a positive link between mindfulness and optimal adaptation including happiness or well-being ${ }^{13-15}$ and mindfulness may directly facilitate happiness. ${ }^{16}$ Hence, it can be said that happiness is a proximate goal or outcome of human life which comes only with a healthy acceptance to the satisfaction and achievement of life.

Despite a large body of research that has emerged related to happiness and mindfulness, surprisingly little work has been done in this field on finding an association between these two. The present article, therefore, seeks to address this gap as a beginning evolutionary and empirical foundation. In this paper, we reviewed the evidence of an association between happiness and mindfulness, with a focus on how mindfulness components can be inculcated 
to optimize the sense of authentic happiness. To the best of our knowledge, no reviews on this issue have been published to date.

\section{Materials and Methods}

This was a non-systematic descriptive literature review. Articles were sourced from PubMed and Google Scholar electronic databases and were not limited by date of publication. Only articles written in the English language were considered. Being a non-systemic review, no specific inclusion and exclusion criteria were laid down for this study, and a critical appraisal of the contribution of the found literature was done to conclude.

\section{Happiness: The Ultimate Quest and Goal of Life}

The concept of happiness has a long culturally, philosophically, and psychologically diverse history and there is not a single universally accepted definition that applies to all people at all times. From a western point of view, to facilitate the proper understanding and universal acceptance of happiness, Diener ${ }^{17}$ proposed the term subjective well-being (SWB) by pioneering the study of happiness which refers to people's subjective appraisals of their lives in terms of well-being that typically include a global assessment of all aspect of a person's life. Later on, Diener and Biswas-Diener ${ }^{18}$ stated that happiness is ultimately not about being happy; it is about being happy to live a rich, varied, and meaningful human existence.

Happiness has also been conceptualized based on two general approaches: hedonic and eudaimonic. ${ }^{19,20}$ Hedonism is related to the importance of positive emotions and life satisfaction, whereas the eudaimonic aspect refers to the optimal psychological functioning of a person, which depends on self-fulfillment and includes the concepts of personal growth, purpose in life, a sense of autonomy, and actualizing one's potential. ${ }^{20-22}$

There are several other perspectives on happiness and wellbeing literature like Csikszentmihalyi and Csikzentmihaly's ${ }^{23}$ concept of flow, Ryff and Singer's ${ }^{24}$ concept of psychological wellbeing, Ryan and Deci's ${ }^{25}$ self-determination theory, and Seligman's ${ }^{8}$ concept of authentic happiness are other prominent contributions on the conceptualization on happiness. Seligman ${ }^{8}$ proposed the term "authentic happiness" and suggested that we can develop unprecedented levels of happiness by identifying and cultivating existing fundamental "signature strengths" such as kindness, generosity, originality, optimism, and humor.

Though the major contribution to happiness has developed from Western literature, other significant conceptualizations exist in Eastern literature. From an eastern perspective, the concept of happiness varies across cultures and has vast literature in Vedas, Upanishads, Yoga, Bhagavad Gita, Buddhism, and other various schools. ${ }^{26}$ In eastern literature, the word "Sukha" is often referred to as the concept of happiness that exists in both Pali and Sanskrit literature (ancient Indian languages) and occurs frequently in ancient Indian and Buddhist literature. Though it seems that Indian and Buddhist literature has a detailed description of happiness, the concept of Sukkha does not seem to capture the concept precisely as compared to the concept "Dukkha". Teasdale and Chaskalson ${ }^{27}$ in their paper beautifully described Buddha's four noble truths which elaborate the analysis of "Dukkha" with great details in terms of nature, origin, and cessation. "Dukkha" is a Pali and Sanskrit word that is often translated into suffering. "Dukkha" has been considered a central existential or survival question of human life since time immemorial. According to Buddha, life is suffering and suffering is universal and unavoidable. He further described that all human beings do experience Dukkha or suffering that is inseparable and an inherent part of our life. Therefore, though Dukkha is related to a wide range of experiencing physical or emotional pain, the experience of Dukkha is itself not a problem rather adding or attaching the meaning and further giving reactions to the ongoing experience of Dukkha is the main source of unhappiness. ${ }^{27,28}$

The pursuit of happiness has been one of the utmost quests and ultimate goals of human existence since time immemorial. The human survival or existential quest for genuine happiness has a long past but the history of the new meaning of happiness is short. ${ }^{29}$ The purpose of our life or existence is to seek happiness ${ }^{30}$ and throughout the history, happiness has been considered to be the ultimate motivation for a human being, therefore, it is a highly subjective state of mind which resides within the experience of the individual. Happiness is also related to optimal growth, SWB, and overall life satisfaction. ${ }^{17,31}$ According to Maslow, ${ }^{31}$ once the basic needs are satisfied, a deep desire for self-actualization rises and the human quest ultimately ends with the achievement of self-actualization and he referred to this peak experience as the experience of happiness.

\section{Mindfulness: A Process of Engagement with Happiness}

Though happiness is a scientifically cumbersome term, it has three distinct defined ways; positive emotion, engagement, and meaning in life ${ }^{8}$ through which people orient their pursuit toward happiness especially the engagement and meaning in life, ${ }^{32}$ and that can be achieved through the practice of mindfulness. Mindfulness practice has its roots in the Buddhism analysis of the concept of Dukkha which can be transformed into Sukkha or happiness through mental training. 27,33

Mindfulness and happiness constructs are increasingly emerging as crucial interrelated constructs in mental health research. Though both mindfulness and happiness are a relatively new area of research, historically they are rooted in ancient wisdom traditions. ${ }^{13}$ Buddha's analysis of the nature and origins of Dukkha or suffering emphasizes the role of mindfulness in happiness and provides a basis for understanding how mindfulness can alleviate suffering and ultimately can lead to sukkha or happiness. ${ }^{27,34-36}$ Furthermore, mindfulness practice is related to positive emotions, ${ }^{37,38}$ positive reappraisal, ${ }^{39}$ life satisfaction, ${ }^{40}$ psychological health, ${ }^{41}$ and psychological well-being. ${ }^{16,42,43}$ Campos et al. ${ }^{14}$ studied the relationship between meditation and happiness and found that the facets related to mindfulness and happiness, i.e., self-compassion are better predictors of happiness.

Human life can never be understood until or unless its highest desires are taken into account. Concerning these needs, mindfulness practice promotes the adaptations of higherorder needs which lead to the ultimate sense of achievement or happiness. ${ }^{31,44}$ Considerable research evidence has found a positive link among mindfulness, positive effects, life satisfaction, and purposeful engagement with life, well-being, self-esteem, and self-actualization needs of a person which finally leads to the ultimate happiness. ${ }^{16,40,45-50}$

Mindfulness meditation has also shown to be a great predictor of psychological well-being and happiness. ${ }^{14,42,51}$ With respect to happiness, Csikszentmihalyi and Csikzentmihaly ${ }^{23}$ described "Flow" as a psychological state of complete absorption in the current experience that suits well with the concept of mindfulness. Moreover, to achieve genuine or authentic happiness, mindfulness 
may play a crucial role as a mediator in identifying and cultivating a person's most fundamental strengths and can facilitate distinct ways of experiencing happiness in the present moment such as positive effects, hedonic and eudaimonic aspects of wellbeing. . $^{13,16,47,52,53}$

Hollis-Walker and Colosimo ${ }^{15}$ found that mindfulness is related to psychologically adaptive variables and that positivism is a crucial attitudinal factor in the mindfulness-happiness relationship. Therefore, people who focus on their present moment experience in other words remain happier than those people whose minds wander away from the moment. However, further studies are needed to explore this relationship and to determine what facets may be correlating and mediating the meditation-happiness relationship. Future research can also be planned to explore the mindfulness-happiness relationship and examine which mindfulness facets are better predictors of happiness.

\section{Discussion}

In this paper, we tried to explore the association between happiness and mindfulness, and how practicing mindfulness can lead to acceptance of authentic happiness. The main goal of human survival or strivings is the pursuit of happiness and therefore it is considered as the ultimate goal, purpose, and outcome of life. Striving for happiness and associated social well-being can be better facilitated or achieved through the practice of mindfulness and can also be considered as a royal road to achieving ultimate happiness. Mindfulness promotes the adaptations of higher-order needs and better cognitive and affective evaluations of lives which in turn lead to positive emotions and ultimately happiness. However, in the present era, it is somewhat difficult to explain what constitutes the universally accepted concept of happiness. The present paper offers an insight into what is currently needed is a wider vision of happiness that is reflective of the totality of things. Just like the concept of happiness, the concept of mindfulness is also a much wider concept that can be applied to almost every aspect of human life.

One of the most universal and distinctive features of mindfulness and happiness is acceptance and self-acceptance is also one of the most important characteristics of a self-actualized person. ${ }^{31}$ New emerging research is shedding light on the pursuit of and engagement with happiness as it is not found in external things at all but is a sense or attitude of acceptance we develop and hold within ourselves. Recent studies have shown that mindfulness may play important roles in well-being and positive emotions associated with happiness. Though current scientific psychological research cannot directly answer the ancient philosophical question of how to live well, it can provide ways to achieve it. Moreover, mindfulness is a new concept and can answer all those philosophical questions related to happiness.

It is only recently, however, that researches in this area have begun to understand the adaptive advantages engendered by positive and negative feelings and thereby contributing to the human evolutionary process. However further investigation is required to resolve some of the outstanding issues in happiness research which seems empirical but is not always directly answerable by scientific inquiry. In essence, the present article provides an advanced understanding of the new emerging ideas of overall well-beings concerning mindfulness and happiness. Finally, it can be said from the paper that if self-actualization and happiness are the utmost need and ultimate goal of life then mindfulness can be considered as the ultimate optimal solution.

\section{Conclusion}

A wide range of views has been expressed in this paper about the extent to which mindfulness can ideally facilitate the process of happiness. The present article not only offers an insight into omissions and gaps within the research area of scientifically unwieldy umbrella terms of happiness and mindfulness but also provides an empirical base and hypothesis for future research attempts especially engagement and meaning in life component of happiness with respect to mindfulness. One important conclusion that emerged from this paper is that happiness can be achieved through realizing our potentials to engage meaningfully in life by applying the practice of mindfulness. Research in this area is still lacking and warrants further investigations that can provide a strong empirical basis for happiness and mindfulness as two new emerging interrelated processes. Future research can also attempt to throw some light on happiness by addressing the question that whether achieving happiness can be an evolutionarily feasible or adaptive phenomenon through the practice of mindfulness.

\section{References}

1. Darwin C, The expression of the emotions in man and animals by Charles Darwin. Murray; 1872/1998.

2. LeDoux JE. Evolution of human emotion: a view through fear. Progress in brain research, vol. 195. Elsevier; 2012. pp. 431-442.

3. Ramachandran VS, Jalal B. The evolutionary psychology of envy and jealousy. Front Psychol 2017;8:1619. DOI: 10.3389/fpsyg.2017.01619.

4. Ekman P. An argument for basic emotions. Cogn Emot 1992;6(34):169-200. DOI: 10.1080/02699939208411068.

5. Nesse RM, Ellsworth PC. Evolution, emotions, and emotional disorders. Am Psycholog 2009;64(2):129. DOI: 10.1037/a0013503.

6. Grinde B. Happiness in the perspective of evolutionary psychology. J Happiness Stud 2002;3(4):331-354. DOI: 10.1023/A:1021894227295.

7. Buss DM. The evolution of happiness. Am Psycholog 2000;55(1):15. DOI: 10.1037/0003-066X.55.1.15.

8. Seligman ME. Authentic Happiness: Using the New Positive Psychology to Realize Your Potential for Lasting Fulfillment. Simon and Schuster; 2004. pp. 59-60.

9. Geher G, Wedberg N. Positive evolutionary psychology: Darwin's guide to living a richer life. Oxford University Press; 2019. pp. 3-28.

10. Kabat-Zinn J. Commentary on Majumdar et al.: mindfulness meditation for health. J Alternat Complement Med 2002;8(6):731-735. DOI: 10.1089/10755530260511739.

11. Shapiro SL, Carlson LE, Astin JA, et al. Mechanisms of mindfulness. J Clin Psychol 2006;62(3):373-386. DOI: 10.1002/jclp.20237.

12. Bishop SR, Lau M, Shapiro S, et al. Mindfulness: a proposed operational definition. Clin Psychol: Sci Pract 2004;11(3):230-241. DOI: 10.1093/clipsy.bph077.

13. CooC, Salanova M. Mindfulness can make you happy-and-productive: a mindfulness controlled trial and its effects on happiness, work engagement and performance. J Happiness Stud 2018;19(6):16911711. DOI: $10.1007 / \mathrm{s} 10902-017-9892-8$.

14. Campos D, Cebolla A, Quero S, et al. Meditation and happiness: mindfulness and self-compassion may mediate the meditationhappiness relationship. Personal Individ Differen 2016;93:80-85. DOI: 10.1016/j.paid.2015.08.040.

15. Hollis-Walker L, Colosimo K. Mindfulness, self-compassion, and happiness in non-meditators: a theoretical and empirical examination. Personal Individ Differen 2011;50(2):222-227. DOI: 10.1016/j.paid.2010.09.033. 
16. Brown KW, Ryan RM. The benefits of being present: mindfulness and its role in psychological well-being. J Personal Soc Psychol 2003;84(4):822. DOI: 10.1037/0022-3514.84.4.822.

17. Diener E. Subjective well-being. Psycholog Bullet 1984;95(3):542-575. DOI: 10.1037/0033-2909.95.3.542.

18. Diener E, Biswas-Diener R. Happiness: Unlocking the mysteries of psychological wealth. John Wiley \& Sons; 2011.

19. Huta V, Ryan RM. Pursuing pleasure or virtue: the differential and overlapping well-being benefits of hedonic and eudaimonic motives. J Happiness Stud 2010;11(6):735-762. DOI: 10.1007/s10902-0099171-4.

20. Ryan RM, Deci EL. On happiness and human potentials: a review of research on hedonic and eudaimonic well-being. Ann Rev Psychol 2001;52(1):141-166. DOI: 10.1146/annurev.psych.52.1.1411995 Oct;69(4):719.

21. Hervás G, Vázquez C. Construction and validation of a measure of integrative well-being in seven languages: the Pemberton happiness index. Health Qual Life Outcomes 2013;11(1):66. DOI: 10.1186/14777525-11-66.

22. Ryff $C D$, Keyes $C L$. The structure of psychological well-being revisited. J Personal Soc Psychol 1995;69(4):719. DOI: 10.1037/00223514.69.4.719.

23. Csikszentmihalyi M, Csikzentmihaly M. Flow: The psychology of optimal experience. New York: Harper \& Row; 1990. pp. 72-76.

24. Ryff CD, Singer B. Psychological well-being: meaning, measurement, and implications for psychotherapy research. Psychother Psychosom 1996;65(1):14-23. DOI: 10.1159/000289026.

25. Ryan RM, Deci EL. Self-determination theory and the facilitation of intrinsic motivation, social development, and well-being. Am Psycholog 2000;55(1):68. DOI: 10.1037/0003-066X.55.1.68.

26. Madhura S, Subramanya P. Concept of contentment in various literatures. Int J Yoga-Philoso, Psychol Parapsyc 2015;3(1):14.

27. Teasdale JD, Chaskalson M. How does mindfulness transform suffering? I: the nature and origins of dukkha. Contempor Buddhism 2011;12(1):89-102. DOI: 10.1080/14639947.2011.564824.

28. Sumedho A, The four noble truths. 1992. pp. 6-11.

29. Nathawat SS. Quest for human happiness. In: Chouhan AK, Nathawat SS, ed. New Facets of Positivism. New Delhi: MacMillan; 2011. pp. 1-9.

30. Lama D, Holiness $\mathrm{H}$, Culter $\mathrm{H}$. The art of happiness: A handbook for living. Sydney: Hodder; 1998. pp. 27-31.

31. Maslow AH. Motivation and personality. Prabhat Prakashan; 1981. pp. 35-58.

32. Peterson C, Park N, Seligman ME. Orientations to happiness and life satisfaction: the full life versus the empty life. J Happiness Stud 2005;6(1):25-41. DOI: 10.1007/s10902-004-1278-z.

33. Ricard M. A Buddhist view of happiness. JL \& Relig 2014;29(1):14. DOI: 10.1017/jlr.2013.9.

34. Germer C. The mindful path to self-compassion: freeing yourself from destructive thoughts and emotions. Guilford Press; 2009. pp. 1-8.

35. Gilbert P. Compassion focused therapy: distinctive features. Taylor \& Francis; 2010. pp. 3-12.

36. Rāhula W. What the Buddha taught. Grove Press; 1974. pp. 16-28.

37. Fredrickson BL, Boulton AJ, Firestine AM, et al. Positive emotion correlates of meditation practice: a comparison of mindfulness meditation and loving-kindness meditation. Mindfulness 2017;8(6):1623-1633. DOI: 10.1007/s12671-017-0735-9.
38. Kiken LG, Lundberg KB, Fredrickson BL. Being present and enjoying it: dispositional mindfulness and savoring the moment are distinct, interactive predictors of positive emotions and psychological health. Mindfulness 2017;8(5):1280-1290. DOI: 10.1007/s12671-017-0704-3.

39. Hanley AW, Garland EL. Dispositional mindfulness co-varies with self-reported positive reappraisal. Personal Individ Differen 2014;66: 146-152. DOI: 10.1016/j.paid.2014.03.014.

40. Kong F, Wang $X$, Zhao J. Dispositional mindfulness and life satisfaction: the role of core self-evaluations. Personal Individ Differen 2014;56:165-169. DOI: 10.1016/j.paid.2013.09.002.

41. Keng SL, Smoski MJ, Robins CJ. Effects of mindfulness on psychological health: a review of empirical studies. Clin Psychol Rev 2011;31(6):1041-1056. DOI: 10.1016/j.cpr.2011.04.006.

42. Baer RA, Lykins EL, Peters JR. Mindfulness and self-compassion as predictors of psychological wellbeing in long-term meditators and matched nonmeditators. J Posit Psychol 2012;7(3):230-238. DOI: 10.1080/17439760.2012.674548.

43. Josefsson T, Larsman P, Broberg AG, et al. Self-reported mindfulness mediates the relation between meditation experience and psychological well-being. Mindfulness 2011;2(1):49-58. DOI: 10.1007/ s12671-011-0042-9.

44. Maslow AH. The nature of happiness. J Humanis Educat Develop 1991;29(3):99-102. DOI: 10.1002/j.2164-4683.1991.tb00009.x.

45. Seear KH, Vella-Brodrick DA. Efficacy of positive psychology interventions to increase well-being: Examining the role of dispositional mindfulness. Soc Indic Res 2013;114(3):1125-1141. DOI: 10.1007/s11205-012-0193-7.

46. Sin NL, Lyubomirsky S. Enhancing well-being and alleviating depressive symptoms with positive psychology interventions: A practice-friendly meta-analysis. J Clin Psychol 2009;65(5):467-487. DOI: $10.1002 /$ jclp. 20593.

47. Garland EL, Farb NA, Goldin P, et al. Mindfulness broadens awareness and builds eudaimonic meaning: a process model of mindful positive emotion regulation. Psycholog Inq 2015;26(4):293-314. DOI: 10.1080/1047840X.2015.1064294.

48. Beitel M, Bogus S, Hutz A, et al. Stillness and motion: An empirical investigation of mindfulness and self-actualization. PersonCentered Experient Psychotherap 2014;13(3):187-202. DOI: 10.1080/14779757.2013.855131.

49. Thompson BL, Waltz JA. Mindfulness, self-esteem, and unconditional self-acceptance. J Rational-Emot Cognitive-Behav Therapy 2008;26(2):119-126. DOI: 10.1007/s10942-007-0059-0.

50. Pepping CA, O'Donovan A, Davis PJ. The positive effects of mindfulness on self-esteem. J Posit Psychol 2013;8(5):376-386. DOI: 10.1080/17439760.2013.807353.

51. Schoormans D, Nyklíček I. Mindfulness and psychologic well-being: are they related to type of meditation technique practiced? J Alternat Complement Med 2011;17(7):629-634. DOI: 10.1089/acm.2010.0332.

52. Ivtzan I, Young T, Martman J, et al. Integrating mindfulness into positive psychology: A randomised controlled trial of an online positive mindfulness program. Mindfulness 2016;7(6):1396-1407. DOI: 10.1007/s12671-016-0581-1.

53. Geschwind N, Peeters F, Drukker M, et al. Mindfulness training increases momentary positive emotions and reward experience in adults vulnerable to depression: a randomized controlled trial. J Consult Clin Psychol 2011;79(5):618. DOI: 10.1037/a0024595. 